\title{
El derecho a la ciudad sostenible ${ }^{1}$
}

\section{The right to sustainable city}

\author{
José Zamorano Wisnes \\ Universidad de Huelva (España) \\ ORCID: https://orcid.org/0000-0002-2631-1793 \\ jose.zamorano@dpub.uhu.es
}

\begin{abstract}
NOTA BIOGRÁFICA
Profesor Contratado Doctor en el Área de Derecho Administrativo de la Universidad de Huelva. Doctor en Derecho por la Universidad de Huelva. Participante en distintos proyectos de investigación. Sus principales líneas de investigación son la ordenación del litoral, tanto del espacio terrestre como marítimo, con especial atención a la franja costera, sobre la que he publicado una monografía y distintos capítulos de libro y artículos científicos en revistas de primer nivel nacional. En relación con la ordenación del territorio y el urbanismo ha publicado diversos artículos sobre la LOUA, el suelo urbanizado y los patrimonios públicos del suelo. Otra línea de investigación es la vivienda, sobre la que ha publicado en la Revista Andaluza de Derecho y prepara actualmente una monografía.
\end{abstract}

\section{RESUMEN}

El artículo tiene por objeto el estudio de las actuaciones en el medio urbano, en la ciudad, como quiera que cualquier intervención en la ciudad afecta a esta globalmente, se reflexiona sobre el derecho a la ciudad, como un derecho ciudadano de participar en la toma de decisiones sobre su futuro, para alcanzar un orden de cosas más justo. Encadenado a lo anterior, el desarrollo sostenible, por ello de forma consecutiva, se estudia la incorporación a nuestro derecho de la noción de desarrollo sostenible, lo que supone un impulso a las actuaciones en el medio urbano, centradas en la ciudad existente, en su rehabilitación, regeneración y reforma, más que en hacer nueva ciudad. En este sentido, la incorporación del desarrollo sostenible ha supuesto un giro copernicano en relación con las políticas sobre el suelo, dejando de ser un instrumento, para ser, lo que siempre debió ser, un recurso natural de primera magnitud.

Las actuaciones en el medio urbano, como acaba de decirse, contemplan las de rehabilitación y las de regeneración y renovación. Por lo que el trabajo se centra en el estudio, en primer lugar, en el conocimiento de las llamadas actuaciones en el medio urbano, a través de las cuales es posible la innovación del planeamiento urbanístico y la ocupación de espacios libres o comunes para mejorar la accesibilidad de las viviendas, entre otras. El régimen jurídico de las mismas, en relación con éste el TRLSRU ha sido poco original, en tanto que la regulación de la participación y ejecución de las actuaciones recuerda sobremanera el sistema de compensación de la legislación urbanística, para finalizar estudiando las actuaciones de rehabilitación urbana y los derechos, vinculados a las anteriores operaciones, de realojo y retorno.

\section{PALABRAS CLAVE}

Derecho a la ciudad; sostenibilidad; participación; rehabilitación; regeneración; renovación.

1 Trabajo realizado en el marco del Proyecto de investigación: Nuevo Derecho Urbanístico: Simplificación, sostenibilidad, rehabilitación. DER2017-84387-P. 


\begin{abstract}
The article aims to study the actions in the urban environment, in the city, as any intervention in the city affects it globally, it reflects on the right to the city, as a citizen's right to participate in the taking decisions about their future, to achieve a more just order of things. In another vein, the incorporation into our law of the notion of sustainable development is studied, which supposes a boost to actions in the urban environment, focused on the existing city, on its rehabilitation, regeneration and reform, rather than on make new city. In this sense, the incorporation of sustainable development has meant a Copernican shift in relation to land policies, ceasing to be a resource, to be, as it always has been, a natural resource of the first magnitude.

The actions in the urban environment, as has just been said, contemplate those of rehabilitation and those of regeneration and renovation. Therefore, the work focuses on the study, first of all, of the study of the so-called actions in the urban environment, through which it is possible to innovate urban planning and the occupation of free or common spaces to improve accessibility. of homes, among others. The legal regime of the same, in relation to the TRLSRU has been little original, while the regulation of the participation and execution of the actions strongly recalls the compensation system of the urban legislation, to end by studying the urban rehabilitation actions and relocation and return operations.
\end{abstract}

\title{
KEYWORDS
}

Right to the city; sustainability; participation; rehabilitation; regeneration; renewal.

\section{SUMARIO}

1. INTRODUCCION. 2. EL DERECHO A LA CIUDAD. 3. LA CIUDAD SOSTENIBLE EN LA LEGISLACIÓN SOBRE EL SUELO. 4. LAS ACTUACIONES EN EL MEDIO URBANO. 4.1. REGLAS PARA LA REALIZACIÓN DE ACTUACIONES EN EL MEDIO URBANO. 4.2. RÉGIMEN JURÍDICO DE LAS ACTUACIONES SOBRE EL MEDIO URBANO. 4.3. LA REHABILTACIÓN EDIFICATORIA. 4.4. LOS DERECHOS DE REALOJO Y RETORNO. 5. CONCLUSIONES.

\section{INTRODUCCIÓN}

La presente investigación tiene por finalidad el estudio de las actuaciones en el medio urbano, definidas en el artículo 2.2 TRLSRU como aquellas que tienen por objeto la rehabilitación edificatoria y las actuaciones de regeneración y renovación urbana, pues partimos de la premisa que estas actuaciones contribuyen o, más bien, son la base necesaria para una utilización racional del recurso natural suelo (art. 45.2 CE). en este sentido, el suelo deja de entenderse como un objeto para las operaciones urbanísticas.

Ahora bien, la ciudad es un todo, es un sistema complejo, de forma que la intervención en una parte incide necesariamente en la ciudad en su conjunto ${ }^{2}$, por ello, su planificación, las decisiones sobre la misma son un derecho ciudadano, el derecho a la ciudad, el derecho, como dijera Lefebvre, a modelar la ciudad de acuerdo con los intereses de la gente que la habita, de los intereses generales y, no de acuerdo con los intereses del mercado. Ello coloca en primer plano el derecho de los ciudadanos, como ente colectivo, a ser parte en las decisiones que afecten a la ciudad, también obviamente, a las que afectan a la rehabilitación de sus viviendas, a la regeneración de los espacios públicos, de las infraestructuras, en busca de un espacio urbano que contribuya a realizar sus derechos de ciudadanía.

Un espacio urbano como el descrito por Lefebvre, necesariamente ha de favorecer el desarrollo urbano sostenible, que integre los requerimientos ambientales, de la economía, sociales y culturales, un espacio en el que se puedan desarrollar derechos fundamentales como la participación, principios rectores, como la salud, la vivienda o el trabajo. Como afirma Menendez Rexach ${ }^{3}$, el principio de desarrollo sostenible tiene «unos objetivos genéricos comunes (erradicar el hambre y la pobreza, garantizar una vivienda digna, etc.) y otros mucho más concretos (ciudad compacta, rehabilitación, eficiencia energética de los edificios, etc.)».

Este trabajo se centra en estudiar los objetivos concretos del desarrollo urbano sostenible que, como acabamos de enunciar, se fijan, entre otros aspectos, en las actuaciones en el suelo urbano con la finalidad

\footnotetext{
2 Gifreu Font, J., 2017, p. 76.

3 Menendez Rexach, A., 2020, pp. 50-51.
} 
de, por un lado, conservar y rehabilitar las edificaciones existentes y, fundamentalmente de aquellas destinadas a vivienda y, de otro, su mejora, desde el punto de vista ambiental, optimizando la eficiencia energética de la mismas, y, por último, desde una óptica social, facilitar la accesibilidad y la movilidad. Desde la perspectiva del espacio público, esas actuaciones tienen por objeto modernizar el entorno urbano en el que las personas realizamos la vida en sociedad, a través de actuaciones de renovación y mejora de las infraestructuras urbanas, de los espacios públicos, de las dotaciones en general. Al estudiar estas actuaciones, forzosamente tenemos que abordar cuestiones procedimentales como las reglas para su articulación y, finalmente, el régimen jurídico de las mismas, terminando por los derechos de los ocupantes legales al realojo y retorno.

\section{EL DERECHO A LA CIUDAD}

El derecho a la ciudad es un término acuñado por Henry Lefebvre en 1967 como el derecho de los ciudadanos a decidir, a crear y producir la ciudad, años después, Harvey dirá que este derecho es «mucho más que la libertad individual de acceder a los recursos urbanos: se trata del derecho a cambiarnos a nosotros mismos cambiando la ciudad. Es, además un derecho común antes que individual, ya que esta transformación depende inevitablemente del ejercicio de un poder colectivo para remodelar los procesos de urbanización. La libertad de hacer y rehacer nuestras ciudades y a nosotros mismos es, como quiero demostrar, uno de nuestros derechos humanos más preciosos, pero también uno de los más descuidados» ${ }^{4}$.

El derecho a la ciudad es un derecho de nuevo cuño, un derecho en proceso ${ }^{5}$, vinculado íntimamente con el derecho a la vivienda, pues la calidad residencial, predicada en el artículo $47 \mathrm{CE}$, no es posible o sería incompleto en urbanizaciones degradadas. Solo en barriadas con equipamientos públicos e infraestructuras urbanas de calidad, con espacios públicos accesibles al conjunto de la población es posible una vida social plena en un entorno de excelencia ${ }^{6}$. Como afirma Parejo Alfonso, la ciudad es «el lugar en el que se crean las condiciones para el desarrollo de la personalidad en sociedad y el derecho se despliega sobre tres ejes fundamentales: a) plenitud de la ciudadanía; b) gobierno democrático y c) la función social de la propiedad y la ciudad» ${ }^{7}$.

Este derecho humano emergente «determina el reconocimiento de un revalorizado estatuto de ciudadanía, derivado de la consideración de la ciudad como espacio público colectivo que garantiza a todos sus habitantes el goce más amplio de los derechos políticos, económicos, sociales, culturales y medioambientales. El derecho a la ciudad se fundamenta en el redescubrimiento de la ciudad como ámbito espacial de convivencia democrática y diversidad, es proclamado y reconocido para asegurar la materialización y realización de la libertad y la igualdad ${ }^{8}$. Como dice la Carta Mundial por el Derecho a la Ciudad ${ }^{9}$ es un derecho de todas las personas «sin discriminación de género, edad, condiciones de salud, ingresos, nacionalidad, etnia, condición migratoria, orientación política, religiosa o sexual».

Se trata por tanto de un derecho colectivo, de los ciudadanos en tanto tal, que les apodera para participar en la toma de decisiones de las cuestiones que afectan al presente y futuro de la ciudad, tales como la elaboración, definición, implementación y fiscalización de las políticas públicas que afectan a las ciudades ${ }^{10}$. Pues, «las ciudades constituyen el núcleo de los actuales desafíos económicos, medioambientales y sociales, [...] son el motor de la economía europea y actúan como catalizadores para soluciones innovadoras y sostenibles» ${ }^{11}$.

El ejercicio de los derechos de libertad, igualdad y participación nos pueden permitir avanzar hacia una ciudad sostenible ambiental, económica, social y culturalmente, hacia una ciudad inclusiva ${ }^{12}$, que integre a los

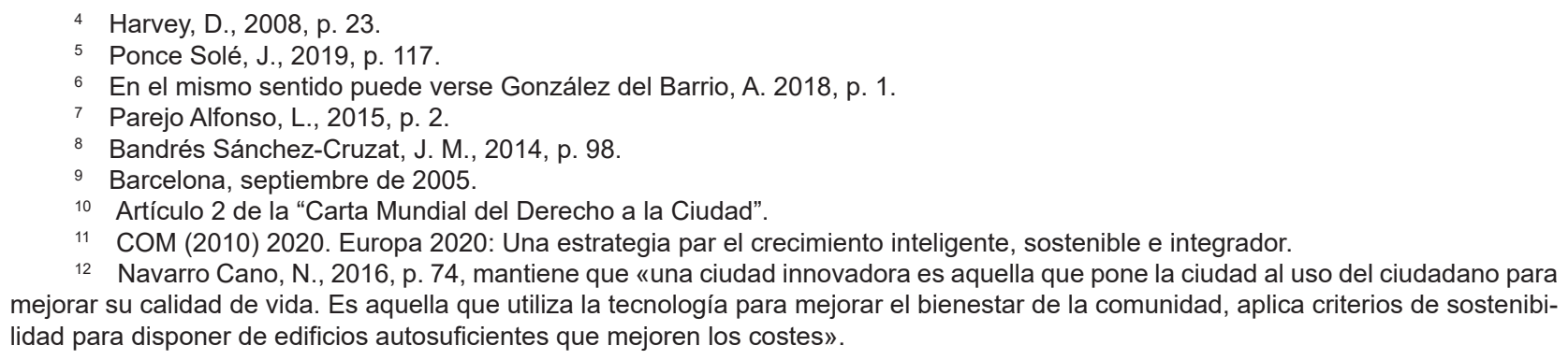

2 Navarro Cano, N., 2016, p. 74, mantiene que «una ciudad innovadora es aquella que pone la ciudad al uso del ciudadano para mejorar su calidad de vida. Es aquella que utiliza la tecnología para mejorar el bienestar de la comunidad, aplica criterios de sostenibilidad para disponer de edificios autosuficientes que mejoren los costes». 
distintos colectivos que en ella conviven, y resilente, es decir, con capacidad de mantener su imagen después de impactos o de catástrofes mientras contribuye positivamente a la adaptación y la transformación ${ }^{13}$. Lo que nos permitiría avanzar hacia la consecución de los Objetivos de Desarrollo Sostenible (en adelante ODS).

La ciudad inclusiva es una necesidad social y jurídica, avanzar hacia esa ciudad para todos, mujeres, niñas, mayores, etc., con dotaciones adecuadas a sus necesidades y más seguras, inclusiva para las personas económicamente más desfavorecidas, en definitiva, es preciso que la ciudad participe en el objetivo de reducir la desigualdad ${ }^{14}$, de hacerse adaptativa para todas las personas que en ella conviven.

En relación con ello, es preciso recordar cómo la legislación impone la realización efectiva del principio de igualdad entre mujeres y hombres, así el artículo 31 de la Ley Orgánica 3/2007, de 22 de marzo, para la igualdad efectiva de hombres y mujeres, establece:

«[...] las políticas urbanas y de ordenación del territorio tomarán en consideración las necesidades de los distintos grupos sociales y de los diversos tipos de estructuras familiares, y favorecerán el acceso en condiciones de igualdad a los distintos servicios e infraestructuras urbanas.».

La consecución de una ciudad sostenible, inclusiva y resilente requiere de la existencia de unos instrumentos de planificación y gestión que se focalicen en dar una respuesta satisfactoria a las necesidades de los ciudadanos y, que genere una gobernanza urbana que convierta al ciudadano en protagonista de los cambios necesarios ${ }^{15}$. O, como dirá Gardini ${ }^{16}$, la ciudad para todos exige partir «de la idea irrenunciable de que el territorio urbano es ante todo un lugar de vida en comunidad y, como tal, sujeto a los poderes públicos de planificación que deben asegurar la función social; se necesita anclar sólidamente la negociación urbanística en la participación democrática, proveniente desde abajo, y emanciparla lo más posible de la propiedad inmobiliaria». En definitiva, las cuestiones planteadas son una de las implicaciones de un derecho más amplio, como es el derecho a la buena administración ${ }^{17}$.

Como afirma Ponce Solé ${ }^{18}$, a través de la planificación urbanística se puede hacer realidad el derecho a la igualdad, lo que resulta una exigencia legal a la vista del precepto mencionado, del artículo 14 de nuestra Constitución y del mandato del artículo 2.2 del TRLSRU. El principio de igualdad que se postula en la legislación urbanística tanto para los ciudadanos, como para los propietarios, cuestión ésta que ha sido objeto de diversas sentencias del Tribunal Supremo, así pueden consultarse la sentencia 22-06-2017 (RC 2263/2016), con invocación de las de 25 de mayo y 23 de junio de 1985, 18 de febrero y 11 de marzo de 1998 y 11 de febrero de 2000.

En este nuevo siglo necesitamos, pues, de nuevos instrumentos, que nos doten de un nuevo urbanismo que se fije más en la rehabilitación y reforma de los barrios existentes, que incida en la redotación de las infraestructuras urbanas, que evite la gentrificación que ya se está produciendo en algunas zonas de nuestras ciudades, es decir, que tenga en cuenta las nuevas necesidades de la población.

En el camino propuesto, hacia la regeneración o renovación de la ciudad existente y la conservación y rehabilitación de nuestras edificaciones, un primer instrumento ha sido la Ley 8/2013, de 26 de junio, de rehabilitación, regeneración y renovación urbanas (L3R), refundida con la Ley 8/2007, de 28 de mayo, de suelo (LS), por el Real Decreto Legislativo 7/2015, de 30 de octubre, por el que se aprueba el texto refundido de la Ley del Suelo y Rehabilitación Urbana (en adelante TRLSRU). No obstante, necesitamos seguir profundizando en la búsqueda de nuevos instrumentos, quizás el planeamiento urbanístico o quizás normas de soft law, dejando, en cualquier caso, como se dijo, el protagonismo a los ciudadanos ${ }^{19}$.

\section{LA CIUDAD SOSTENIBLE EN LA LEGISLACIÓN SOBRE EL SUELO}

La ciudad durante buena parte del siglo XIX y, prácticamente la totalidad del siglo XX ha crecido de forma constante, en los primeros tiempos, para dar respuesta a las necesidades de vivienda de los habitantes del campo que emigraban a las ciudades llamados por el crecimiento económico derivado de la revolución in-

13 ONU Hábitat. Por un mejor futuro urbano.

14 Véase la Declaración de Quito sobre ciudades y asentamientos humanos sostenibles para todos.

15 En el mismo sentido, puede verse Ponce Solé, obra citada, pp. 140 y 141.

16 Gardini, G., 2020, p. 217.

17 Ibídem.

18 Ponce Solé, J., 2013, p. 46.

19 En este sentido Alonso Ibañez, M. R., 2020, p. 134. 
dustrial, en un segundo momento, para mejorar las condiciones de vida de sus moradores y, finalmente, con un carácter eminentemente especulativo. En este contexto, el urbanismo ha sido el instrumento adecuado para canalizar la expansión de las ciudades, que han sido objeto de un proceso de crecimiento continuo ${ }^{20}$ y, como consecuencia de ello, han padecido un proceso progresivo de pérdida de su identidad ${ }^{21}$. Nuestras ciudades han crecido exponencialmente, por ello el suelo urbanizable, el suelo natural capaz de transformarse en nueva ciudad ha sido el protagonista del derecho urbanístico, en él se han concentrado las instituciones más elaboradas de nuestro ordenamiento jurídico: estándares urbanísticos, cesiones, obligaciones de los propietarios, etc., estos instrumentos ideados como técnicas urbanísticas, tuvieron la cualidad de aportar la financiación necesaria para la realización de ese proceso de creación de «nueva ciudad».

En el siglo XXI, el protagonista de nuestro derecho urbanístico debe ser el suelo urbano, la ciudad. La expansión de las ciudades se ha detenido ${ }^{22}$ o debe detenerse, como manifiesta Menéndez Rexach, las transformaciones de suelo rural «en lo sucesivo deberían ser, si no excepcionales, sí, al menos, suficientemente justificadas» ${ }^{23}$. Verdaguer ${ }^{24}$, establece con precisión alguna de las características del sistema urbanístico imperante en nuestro Estado durante todo el siglo XX, en el que se produce una supeditación explícita de la planificación a las estrategias económicas de un modelo basado en el consumo de recursos, una legislación urbanística basada en la vocación de urbanizable del suelo y en la consideración prioritaria del valor de cambio sobre el valor de uso del mismo, lo que se traduce en una desatención a todos aquellos usos no susceptibles de generar plusvalías, una consideración reduccionista y unidireccional de lo ambiental basada exclusivamente en el impacto de los procesos urbanísticos sobre la naturaleza.

La afirmación de la innecesaridad de nuevos consumos de suelo se ve confirmada por nuestra demografía, que pone de manifiesto una tendencia a crecimientos vegetativos cercanos a cero o, incluso, negati$\mathrm{vo}^{25}$. Una demografía que, por otro lado, pone de manifiesto cambios de tendencia importantes, como lo es, sin duda, el envejecimiento de la población que, en consecuencia, se hace más dependiente y requiere de unas dotaciones distintas, unos espacios públicos e instalaciones colectivas específicas. Ello hace preciso adaptar o renovar las dotaciones creadas para una estructura de población más joven y, eso afecta tanto a las dotaciones públicas (necesidad de centros para personas dependientes) y privadas (vivienda, donde resolver los problemas de accesibilidad, de movilidad es un reto para el urbanismo actual).

Por otro lado, esa nueva política hacía la ciudad debe ser ambientalmente más eficiente, limitando el consumo de recursos naturales ${ }^{26}$, la tecnología facilita cada vez más la reutilización de algunos de los bienes consumidos, el nuevo urbanismo sostenible debe tender a hacer una ciudad que propicie menores consumos ambientales (suelo, agua, aire) y la generación de residuos de acuerdo, cuando menos, con la jerarquía de objetivos prevista en la Ley 22/2011, de 28 de julio, de residuos y suelos contaminados (prevención, preparación para la reutilización, reciclado, otro tipo de valorización y eliminación segura) ${ }^{27}$.

Estos propósitos de desarrollo sostenible se ven recogidos en el TRLSRU, que hacen del desarrollo sostenible uno de sus objetivos, de los hilos conductores de la Ley ${ }^{28}$, así resulta suficientemente explicita la declaración contenida en su artículo 1, que por su importancia recogemos textualmente, afirma el referido precepto que, la Ley tiene por objeto garantizar:

«Un desarrollo sostenible, competitivo y eficiente del medio urbano, mediante el impulso y el fomento de las actuaciones que conducen a la rehabilitación de los edificios y a la regeneración y renovación de los tejidos urbanos existentes, cuando sean necesarias para asegurar a los ciudadanos una adecuada calidad de vida y la efectividad de su derecho a disfrutar de una vivienda digna y adecuada.».

20 Moreno Molina, A. M., 2008, p. 18. En igual sentido Bustillo Bolado, R. O., 2014, p. 119.

21 En el mismo sentido Gardini, G., 2020, pp. 165 y 166.

22 Véase la "Exposición de motivos" de la Ley de Ordenación Urbanística de Andalucía.

23 Menéndez Rexach, A., 2011, pp. 14 y 15.

24 Cita recogida en Alonso Ibañez, M. R., 2020, pp. 148 y 148.

25 Una opinión similar puede verse en Menéndez Rexach, A., 2009, p. 123.

26 En igual sentido Bustillo Bolado, R. O., 2014, pp. 120 y 124 y 125, donde contempla algunos ejemplos para reducir el consumo de recursos naturales en algunas dotaciones urbanas.

27 Sobre la prevención y eliminación de residuos puede verse Alenza García, J. F., 2018, pp. 270 y 271.

28 Opinión compartida con Cuyas Palazón, M., 2018, p. 147. En igual sentido Vaquer Caballería, M., 2007, p. 36. Más crítico se muestra López Ramón, F., 2007, p. 18, quien opina que en los preceptos de la LS de 2007 existe una carga ideológica demasiado genérica con respecto a los principios del urbanismo sostenible, por lo que duda que sea suficiente para superar la fuerza de la tradición desarrollista. 
Objetivo que se apuntala en el artículo 3, que con el título de "Principio de desarrollo territorial y urbano sostenible" 29 , dispone que todas las «políticas públicas relativas a la regulación, ordenación, ocupación, transformación y uso del suelo tienen como fin común la utilización de este recurso conforme al interés general y según el principio de desarrollo sostenible», en virtud del cual, dichas políticas «deben propiciar el uso racional de los recursos naturales armonizando los requerimientos de la economía, el empleo, la cohesión social, la igualdad de trato y de oportunidades, la salud y la seguridad de las personas y la protección del medio ambiente».

En consecuencia, el TRLSRU entiende por desarrollo sostenible, aquel que hace compatibles «un crecimiento elevado y estable de la producción de bienes y servicios con un progreso social extendido, una protección del medio ambiente y un uso prudente y eficiente de los recursos naturales» ${ }^{30}$, sin que ninguno prevalezca sobre los otros. Concretando que esas políticas en el medio urbano deben armonizarse con los principios de competitividad y sostenibilidad económica, social y medioambiental, cohesión territorial, eficiencia energética y complejidad funcional.

Cuyas Palazón, se plantea la razón por la cual el legislador ha optado por definir el desarrollo sostenible con la amplitud que lo hace el artículo 3, llegando a la conclusión que la misma trae causa en el cambio de paradigma del suelo, que, de ser la base operativa del urbanismo, ha pasado a ser un recurso ambiental básico. «El urbanismo, actor principal que tenía por objeto el suelo, pasa a jugar un papel instrumental. El suelo, que era el mero objeto del urbanismo, toma el papel esencial, pero no en el urbanismo, sino del derecho ambiental en cuanto a recurso ambiental esencial [...]» ${ }^{31}$.

Esta noción del desarrollo sostenible es la que sostiene el Tribunal Supremo en su sentencia de 20 de diciembre de 2006 (RC 765/2004), donde se afirma que el desarrollo sostenible:

[...] proclamado por primera vez en la conferencia de Estocolmo que pretende equilibrar el máximo de protección natural sin renunciar al mayor desarrollo posible, buscando proteger los recursos naturales, sin menoscabo de su necesaria explotación en aras a un desarrollo social y económico ordenado, esto es, consolidar un desarrollo socialmente deseable, económicamente viable y ecológicamente prudente $[\ldots]^{32}$.

A fin de favorecer la consecución de los objetivos de desarrollo sostenible propuestos, las políticas públicas deben combinarse de forma funcional, de modo que se posibilite el uso residencial en viviendas y entorno urbano seguro, saludable, accesible, de calidad, integrado, provisto de equipamientos que minimicen el impacto de las emisiones contaminantes y los gases efecto invernadero, optimicen el consumo de agua, energía y la eliminación de residuos, integrando en el tejido urbano los usos compatibles con su función residencial. Favorecer la dinamización económica y social, la rehabilitación y la ocupación de viviendas vacías; la calidad y funcionalidad de las dotaciones; la movilidad primando la pública colectiva y potenciando los desplazamientos peatonales y en bicicleta (artículo 3.3). De modo, que la Ley recoge con claridad los diversos elementos del desarrollo sostenible: el desarrollo social, económico, medioambiental y cultural.

EI TRLSRU no se queda en esa declaración de principios, sino que buena parte de los elementos enumerados se desarrollan a través del texto de éste, nosotros nos vamos a fijar en aquéllos que hacen referencia a la utilización del suelo urbano y, fundamentalmente, a las actuaciones de regeneración y rehabilitación. En este sentido resulta de especial importancia el artículo 20.1.a), donde se insiste en la necesidad de profundizar en las políticas de regeneración urbana, al limitar las posibilidades de transformación del suelo rural en urbanizado, «al suelo preciso para satisfacer las necesidades que lo justifiquen, impedir la especulación con él y preservar de la urbanización al resto del suelo rural». A su vez, el apartado c) del mismo artículo, dispone que la ordenación de los usos del suelo debe responder a los principios de accesibilidad universal, igualdad de trato y de oportunidades entre mujeres y hombres, de movilidad, de eficiencia energética, de garantía de suministro de agua, de prevención de riesgos naturales y de accidentes graves, de prevención y protección contra la contaminación y limitación de sus consecuencias para la salud o el medio ambiente.

Principios, todos ellos, que han sido acogidos por la jurisprudencia del Tribunal Supremo, en supuestos en que los planes habían previsto el paso del suelo rural a urbanizado, superficies de suelo superiores a las

29 Sobre la recepción del principio de urbanismo sostenible por nuestra legislación de Suelo puede consultarse Moreno Molina, A. M., obra citada, pp. 58 a 62 y Menéndez Rexach, A., 2020, pp. 66 a 91.

30 Fernández de Gatta Sánchez, D., 2016, p. 5.

31 Cuyas Palazon, M., 2018, p. 149. Una opinión similar puede verse en Sánchez Goyanes, E. (2007a), p. 151, Menéndez Rexach, A., 2009, p. 131, y también Alonso Ibañez, M. R., 2012, p. 25.

32 Citada por Bustillo Bolado, R. O., 2014, p. 38, como la primera vez que la jurisprudencia define el concepto de desarrollo sostenible. 
necesarias para satisfacer las necesidades de crecimiento de la población, de acuerdo con la justificación contenida en el mismo plan, han dictado sentencias declarando la nulidad de los mismos o cuando menos a la anulación de los preceptos que suponían ese incremento del suelo a urbanizar, así las sentencias de 18 de junio de 2015 (RC 3436/2015), 24-06-2015 (RC 3784/2013) o 27-09-2018 (RC 2339/2017), la primera de ellas en su fundamento jurídico $15 .^{a}$, afirma:

«La recepción del principio de desarrollo territorial y urbano sostenible en la Ley estatal 8/2007, de suelo, y en el Texto refundido vigente, aprobado por Real Decreto Legislativo 2/2008, de 20 de junio, pretende desplazar la tradicional concepción desarrollista impulsora de un crecimiento urbano ilimitado por otra que lo controle, insistiendo en la regeneración de la ciudad existente, frente a las nuevas transformaciones de suelo, si bien partiendo de la premisa de que desde la legislación estatal no se puede imponer un determinado modelo urbanístico.».

Esta línea se apuntala en el artículo 22 TRLSRU, que contempla la realización de estudios de evaluación ambiental, así como informes sobre el seguimiento de la actividad urbanística y su sostenibilidad ambiental y económica. El sometimiento de los planes urbanísticos a EAE contemplada en el artículo 22.1 es coherente con la prescripción de la Ley 21/2013, de 9 de diciembre, de Evaluación Ambiental (en adelante LEA), y la no realización de la misma o su realización incorrecta ha supuesto la declaración de nulidad del Plan. En tal sentido puede verse, entre otras, las SSTS 20-02-2015 (RC 1012/2013) y 27-10-2015 (RC 2180/2014), en esta última se anula el Plan General de Marbella que realizó la evaluación ambiental del Plan de acuerdo con la normativa andaluza (Evaluación de Impacto Ambiental), por lo que el Tribunal Supremo tras comprobar las diferencias entre la EIA y el EAE declara la nulidad del Plan por falta del preceptivo estudio ambiental.

Con el objetivo de hacer un seguimiento de las prescripciones urbanísticas y de las prevenciones ambientales, el número 6 del indicado artículo 22, obliga a realizar un informe periódico que debe elevarse al órgano colegiado de gobierno, normalmente el Pleno, informe que versará sobre la ejecución urbanística del municipio, y que debe contemplar la afectación a la sostenibilidad ambiental y económica. Este documento de seguimiento puede surtir efectos previstos por la legislación de evaluación ambiental, siempre que cumplan los requisitos de dicha legislación.

En definitiva, como hemos apuntado en las líneas anteriores, los objetivos del desarrollo sostenible están claramente identificados en la legislación sobre el suelo y ampliamente compartidos por la doctrina y jurisprudencia especializada, por lo que esperamos que su consecución sea realizable con mayor facilidad ${ }^{33}$. En la misma línea, Moreno Molina, mantiene que una vez recogido por las leyes sectoriales el principio de desarrollo sostenible corresponde al complejo Gobierno-Administraciones Públicas materializarlo, hacerlo efectivo, a través de las actividades de programación y planificación ${ }^{34}$.

Como quiera que, la consecución de estos objetivos depende en buena medida de las políticas que se practiquen en la ciudad consolidada, parece conveniente centrar nuestro estudio en los instrumentos que la Ley pone a disposición del planificador urbanístico para su reactivación, centrando el nuevo urbanismo, la satisfacción de las necesidades de vivienda y de tejidos urbanos más amables y humanos en las actuaciones en suelo urbanizado, mientras que las políticas sobre el suelo rural, deberán centrarse en la protección de su naturalidad, en favorecer el desarrollo de sus potencialidades naturales, etc.

En consecuencia, los próximos epígrafes los vamos a centrar en el estudio de las actuaciones en el medio urbano.

\section{LAS ACTUACIONES EN EL MEDIO URBANO}

Las actuaciones en el medio urbano pueden ser de dos tipos, rehabilitación edificatoria [artículo 2.1 en relación con el 7.2.b) TRLSRU] y las de regeneración y renovación urbana (artículo 2 en relación con el 7.1 del TRLSRU).

Las primeras se definen como aquellas que afectan a la edificación y tiene por objeto trabajos de mantenimiento o, en general, de intervención en la edificación, sus instalaciones o espacios comunes para corregir los déficits de funcionalidad, seguridad y habitabilidad de la construcción. Se trata de una definición amplia que incluye tanto los trabajos de mantenimiento, es decir, de conservación en sentido estricto, como los que

33 Alonso lbañez, M. R., 2012, p. 24

34 Moreno Molina, obra citada, pp. 67 y 68. 
supongan una actuación más profunda en la edificación con el objeto de mantener sus características esenciales y, en consecuencia, la edificación misma. O, incluso, de renovación de la edificación y su sustitución por otra nueva. La misma puede incluir actuaciones de regeneración y renovación urbana que no se puedan clasificar como actuaciones de transformación, conforme lo que se dirá a continuación. El Plan Estatal de Vivienda (PEV) en vigor hasta finales del presente año, aprobado por Real Decreto 106/2018, de 9 de marzo, establece ayudas para las denominadas áreas de «regeneración y renovación urbana y rural», cuyo objeto es financiar «la realización conjunta» de obras de rehabilitación de edificios y de urbanización o reurbanización.

Las actuaciones de transformación urbanística que supongan la regeneración y renovación urbanas son aquellas que integran, tanto las actuaciones de urbanización [artículo 7.1.a) 2)], es decir, aquellas que tengan por objeto una reforma o renovación del tejido urbano, mediante la transformación del ámbito geográfico previamente definido, para crear una o más parcelas aptas para edificar, como aquellas actuaciones de dotación [artículo 7.1.b)] ${ }^{35}$, es decir, que supongan una actuación más conservadora en el suelo urbano, pues están llamadas a incrementar las dotaciones existentes, este incremento trae causa en un incremento de la edificabilidad del área, o de la densidad o, un cambio de los usos establecidos por la ordenación urbanística, con el objetivo de mejorar la ciudad, y no de transformarla. A nuestro juicio, nada impide, actuaciones de renovación urbana que tengan por objeto exclusivamente la mejora de las infraestructuras urbanas (calles, plazas, parques y jardines, etc), o de las dotaciones existentes. Sin embargo, estas actuaciones no están reguladas en el TRLSRU, ni financiadas con cargo al PEV vigente.

Cualquiera de estas actuaciones de regeneración y renovación podrán tener carácter integrado cuando además articulen medidas ambientales, sociales y económicas ${ }^{36}$, compartimos la crítica de Gifreu Font ${ }^{37}$, en el sentido de que el legislador estatal debería haber incidido más en estas actuaciones integradas, con una visión holística, que aborde las actuaciones en el suelo urbano tanto desde un punto de vista urbanístico, como ambiental, social y económico, pues solo así, con soluciones integrales podrán abordarse problemas que, en la mayoría de los casos no son solo urbanísticos, sino también son globales y, por tanto, las soluciones exclusivamente urbanísticas no remediarán.

La jurisprudencia ha intentado delimitar unas actuaciones de otras en las SSTS de 20-07-2017; 30 10-2018 (RC 6090/2017) y más recientemente la sentencia de 14-02-2020 (RC 6020/2017), definiendo las diferencias entre las actuaciones de urbanización y las de dotación ${ }^{38}$, así afirma:

«Esto es, el nivel de la actuación -y sus correspondientes consecuencias- no viene determinada por el nivel o grado de pormenorización del suelo a transformar, sino por el grado o nivel de la transformación que se realice sobre un determinado suelo, y que, en función de su intensidad, podrá consistir en una reforma o renovación de la urbanización, o, simplemente, en una mejora de la misma mediante el incremento de las dotaciones, en un marco de proporcionalidad, y sin llegar a la reforma o renovación; la reforma o renovación (Actuación de urbanización) es "hacer ciudad" -cuenta con un plus cualitativo-, y el incremento de dotaciones (Actuación de dotación) es "mejorar ciudad", con un componente más bien cuantitativo».

La jurisprudencia, que acabamos de citar, deja en manos del planeamiento urbanístico la decisión de intervenir sobre el suelo urbano con una de estas actuaciones, pero esta decisión deberá estar suficientemente motivada, así afirma que «es posible que el planificador decida actuar sobre ámbitos que ya son ciudad para ejecutar sobre ellos actuaciones de renovación, rehabilitación o regeneración urbanas, pero para ello será exigible que se motive, con una motivación reforzada, la concurrencia de tal circunstancia en la propia Memoria del plan y la conveniencia, en aras de los intereses públicos siempre que tales actuaciones respondan a necesidades reales, evitando así que la mera voluntad transformadora basada en criterios de mera oportunidad, provoque efectos sobre los deberes de los propietarios que ya contribuyeron a la consolidación de los terrenos donde se ubican sus viviendas o locales».

35 Las actuaciones de regeneración urbana son para Menéndez Rexach, A., 2014, p. 5, un imperativo del desarrollo sostenible.

36 Para Tejedor Bielsa, J., 2015, p. 11, este carácter integrado no debe ser una posibilidad, sino una necesidad para evitar que la regeneración de nuestras ciudades se haga a costa la población actual del espacio urbano, que, habitualmente, «es de edad avanzada y/o de bajo poder adquisitivo cuando no perteneciente a colectivos excluidos o en riesgo de exclusión social». Alonso Ibañez, M. R., 2016, pp. 44 y 45, apunta cuales deberían ser los elementos clave para lograr un desarrollo urbano integrado.

37 Gifreu Font, J., 2017, pp. 76-77.

38 Un estudio más completo sobre la jurisprudencia señalada y la anterior sobre suelo urbano consolidado y no consolidado puede verse en Zamorano Wisnes, J., 2015. 
En consecuencia, las actuaciones en la ciudad para la renovación o reforma de esta o la mejora de sus dotaciones exigen, en primer lugar, de una previsión normativa en el planeamiento urbanístico que debe motivar la necesidad de esta, lo que produce, como consecuencia, la participación en la gestión del plan de quienes sean titulares de las edificaciones, viviendas, etc. Y, la obligación de contribuir a los costes de las mismas, con independencia de la naturaleza previa de los suelos ${ }^{39}$.

Esta participación en la gestión de los propietarios de suelo o edificaciones a que se refiere el artículo 9 , en sus apartados 3 y 4 TRLSRU, debe completarse con la participación de los ciudadanos en general en la definición de las actuaciones de renovación y rehabilitación, pues como afirma la jurisprudencia, la ciudad es de todos por lo que «el diseño de los espacios habitables, de sus usos y de sus equipamientos, y de las perspectivas de su desarrollo, ampliación o expansión, sirva con objetividad los intereses generales; no los intereses de uno o de unos propietarios; ni tan siquiera los intereses de la propia Corporación Municipal» [STS 26-07-2006 (RC 2393/2003), entre otras muchas].

\subsection{Reglas para la realización de actuaciones en el medio urbano}

El artículo 24 TRLSRU fue objeto de una importante jibarización por la STC 143/2017, que declaró la inconstitucionalidad por razones competenciales de los números 2 y 3 . Por lo que el mismo ha quedado reducido a los números $1,4,5$ y 6 .

No obstante, lo que acabamos de decir, el referido precepto en la parte que sigue vigente contiene una serie de reglas comunes para las actuaciones en el medio urbano, ya sean estas sobre la edificación, sobre la urbanización o sobre ambas, que conviene estudiar con detenimiento e, incluso la parte más procedimental que ha sido objeto de anulación se ve suplementada por la reglas establecidas en el art. 25, además, obviamente de la regulación que de esta cuestión realicen o, han realizado, las CCAA.

El artículo citado recuerda a la ordenación contenida en el artículo 96 del Real Decreto Legislativo 1/1992, de 26 de junio, por el que se aprueba el Texto Refundido de la Ley sobre Régimen del Suelo y Ordenación (TRLS de 1992). En su afán de facilitar las actuaciones en el medio urbano, prevé la posibilidad de que su realización no esté prevista en el planeamiento urbanístico, en este caso, es preciso comenzar por la modificación del planeamiento, para lo cual el legislador estatal, dada su falta de competencia en materia urbanística, se remite a la legislación urbanística de las CCAA, con el objeto de que éstas definan el contenido y procedimiento de dichas modificaciones. Permitiendo, incluso, que tales actuaciones se aprueben por instrumentos distintos al planeamiento urbanístico, siempre que así lo establezca la legislación urbanística de las CCAA.

Posibilidad que tampoco es desconocida en nuestro derecho urbanístico, pues tradicionalmente ha utilizado los planes generales o especiales para la ordenación del suelo urbano, así la Ley 7/2002, de 17 de diciembre, de Ordenación Urbanística de Andalucía (LOUA), pues bien, estos últimos incluyen entre sus objetivos, la posibilidad de incorporar medidas para conservar, mejorar o protejer el medio urbano, incluso cuando no haya un plan general previo al que desarrollar [art. 14.2.b)].

EI TRLSRU, impone que sea cual fuere el instrumento urbanístico a utilizar será preciso la realización de un informe de sostenibilidad económica, de modo que asegure la viabilidad económica de la actuación y que la misma no altere el equilibrio presupuestario del municipio ${ }^{40}$, en los términos previstos en el número 5 del artículo 22, con ello la Ley ha pretendido reforzar el valor de estos informes, dado que los estudios económico-financieros de los planes se han convertido en un documento formal que nada aporta al estudio de la viabilidad económica y del mismo.

De no ser precisa la modificación del planeamiento, normalmente porque el Plan ya prevea la concreta actuación sobre el medio urbano, será necesario, en cualquier caso, la aprobación de la delimitación del ámbito de «actuación conjunta» que podrá ser, dice la Ley, continúo o discontinúo. En este supuesto, nos moveríamos en lo que la legislación urbanística denomina actuaciones sistemáticas o por unidades de ejecución, las referencias a la legislación urbanística se harán, en lo sucesivo, a la LOUA.

39 No coincido con las consideraciones de Iglesias González, F., 2015, pp. 123 a 127, en el sentido de que las cesiones urbanísticas debieran regularse de forma más o menos rígida por el Estado, sin entrar ahora en la cuestión competencial, el establecimiento de unas dotaciones tasadas al modo del anexo del Reglamento de Planeamiento no produce sino desajustes entre las necesidades reales de la población y las previsiones normativas. A título de ejemplo, baste con citar como unas ciudades cada vez más envejecidas se ven obligadas a realizar reservas de suelo para dotaciones escolares, mientras que las previsiones para centros de asistencia a las personas mayores son inexistentes o muy reducidas.

40 Ver Gifreu Font, J., 2017, p. 81 y 82, también Alonso Ibañez, M. R., 2017, pp. 95-106. 
Junto a ellas, el legislador estatal regula las actuaciones asistemáticas (artículo 24.1), que a nuestro juicio en el ámbito urbano tendrán una notable importancia, piénsese, p. e. en actuaciones para mejorar la accesibilidad de determinadas edificaciones o el aprovechamiento energético. En ambos supuestos, la delimitación del ámbito de actuación o de la actuación aislada se realizará a propuesta de alguno de los sujetos enumerados en el artículo 8 TRLSRU.

Tanto para las actuaciones sistemáticas, como para las asistemáticas es imprescindible la adopción de un acuerdo administrativo, que delimite el ámbito de actuación, se trata de un acto administrativo cuyo procedimiento de aprobación, requiere la notificación a los interesados y un trámite de información pública, para su posterior aprobación. Es cierto, que como dijimos, el número 2 del artículo que estamos estudiando ha sido declarado nulo, no obstante, esa necesidad de notificación y publicación se infiere, sin lugar a duda, de lo previsto en el art. 25 TRLSRU, además de las previsiones concretas contenidas en la legislación urbanística de las CCAA. Como tampoco ofrece dudas que los propietarios afectados por la delimitación de ámbito de actuación participan en la misma en un régimen de equidistribución de beneficios y cargas (artículo 14.c)], en virtud del principio de transparencia, aun cuando, como sabemos, para estos propietarios, la participación en la actuación es un deber del que no pueden sustraerse (art. 17.2).

Los números siguientes del artículo que estamos comentando, establecen una serie de reglas para facilitar la rehabilitación de las edificaciones más antiguas existentes en el suelo urbano ${ }^{41}$. Las más antiguas $y$, probablemente, las ocupadas por personas de mayor edad $y$, consecuentemente, con un mayor grado de dependencia, además de posiblemente las económicamente más desfavorecidas, por lo que nos parece un paso importante hacia la sostenibilidad urbana y social. Así, el número 4 del indicado precepto autoriza la ocupación de espacios libres o de dominio público para la instalación de ascensores u otros elementos que garanticen la accesibilidad universal. Esta autorización de ocupación se extiende a elementos privativos tales como vestíbulos, descansillos, sobrecubiertas, voladizos y soportales tanto en el suelo, como en el subsuelo o en el vuelo, a condición de que sea la única solución viable técnica o económicamente. De esta forma, la Ley sacrifica las dotaciones públicas e, impone un sacrificio a los propietarios privados que pueden sufrir la perdida de una parte de su vivienda, en favor de unas viviendas más accesibles y que favorezcan la movilidad.

Obviamente, ese sacrificio en la propiedad privada de las viviendas tiene que ser compensado y, de no poder serlo, mediante los mecanismos de equidistribución, tiene que serlo acudiendo a los mecanismos de expropiación, o a la adquisición, mediante convenio, por parte de los beneficiarios de la actuación de la parte ocupada de la vivienda.

Esos mismos criterios de autorización de ocupación del espacio público o privado, se establecen sobre los espacios necesarios para la realización de obras que consigan reducir al menos un 30 por ciento la demanda energética de calefacción o refrigeración del edificio, mediante instalaciones que tengan por objeto la instalación de aislamiento térmico o fachadas ventiladas; la instalación de dispositivos bioclimáticos; la instalación de sistemas de energía renovable o la reducción del consumo de agua. En este caso, la Ley supone un claro incentivo por mejorar la calidad de vida mediante la reducción de la contaminación que produce la ciudad, incidiendo en los elementos que más contribuyen a ésta, aún cuando ello suponga un sacrificio temporal para el espacio público. También en este caso, si ese sacrificio se produce sobre elementos privativos y es de carácter definitivo debe ser compensado mediante, normalmente, los mecanismos de la expropiación, estamos pensando, p. e. en la instalación de placas solares en una terraza de uso privativo.

Estas previsiones se complementan con una regla excepcional, al requerir de los planes urbanísticos, que establezcan normas, criterios, para que estas superficies no computen a efectos de los límites de edificabilidad establecidos por el planeamiento urbanístico, ni a las distancias mínimas a linderos.

Las mismas reglas se aplican a las obras que consigan reducir en al menos un $30 \%$ la demanda energética anual de calefacción o refrigeración del edificio, siempre que las mismas consistan en alguna de las actuaciones enumeradas en el apartado 5 del indicado artículo.

Finalmente, se prevén actuaciones en inmuebles de interés cultural, limitándose la Ley a autorizar «soluciones innovadoras» que den solución a los problemas de accesibilidad o ahorro energético.

La LOUA establece en sus artículos 144 a 147 la ejecución mediante áreas de gestión integradas $(\mathrm{AGI})^{42}$, que puede resultar interesantes para la ejecución de actuaciones en el medio urbano, sobre todo

41 Aspectos destacados por Gifreu Font, J., 2017, p. 79.

42 Para Castellvi Martínez (Gutierrez Colomina, V. et al., 2004, p. 890), se trata de un instrumento para la colaboración entre Administraciones en la gestión y ejecución del planeamiento. 
para las llamadas actuaciones integradas (artículo 2.1 TRLSRU) en las que se integran, como se dijo, las actuaciones urbanísticas y edificatorias, con otras de carácter social, ambiental o económico. Pues bien, el establecimiento de estas áreas puede realizarse por el planeamiento urbanístico o por el procedimiento de delimitación de unidades de ejecución, con lo que las previsiones de la LOUA son coincidentes con las que acabamos de ver del TRLSRU.

La delimitación de la AGI supone la «coordinación e integración de acciones de la Administración de la Junta de Andalucía y los municipios, así como, en su caso, las restantes Administraciones con incidencia en los objetivos perseguidos con dichas áreas» ${ }^{43}$.

El artículo 145 determina los efectos de la declaración de AGI, en primer lugar, la cooperación de las distintas Administraciones implicadas, la autorización para constituir consorcios de gestión del área, así como para recaudar, por la AGI, precios públicos y, la utilización y administración de los bienes aportados o adscritos a la misma. Y, por último, el sometimiento al ejercicio de los derechos de tanteo y retracto de todas las transmisiones producidas en el área en un periodo de seis años.

El artículo 147, a su vez, autoriza para que el área se divida en una o varias unidades de ejecución, con aplicación en cada una de ellas de cualquiera de los sistemas de ejecución del planeamiento previstos en la LOUA, o/y la realización de obras ordinarias.

Esta normativa debe ser completada con la previsión contenida en vigente PEV, citado, cuyos artículos 47 a 54 contemplan ayudas para las Áreas de Regeneración y Renovación Urbanas (ARU), el objeto de las mismas son las actuaciones conjuntas de rehabilitación de edificaciones y urbanización o reurbanización de espacios públicos o, incluso, de edificaciones de nueva planta en sustitución de otros demolidos, incluyendo actuaciones en ámbitos de infravivienda y chabolismo (artículo 47). Para que la ARU sea subvencionable el Plan establece como condición que el $70 \%$ de la edificabilidad sobre rasante de la ARU sea dedicada a vivienda, requisito del que exceptúa las actuaciones que afecten a infravivienda o chabolismo, esta regulación resulta a mi juicio incompleta, pues ¿qué pasa en el supuesto de actuaciones en las que se incluyan viviendas e infraviviendas?

Como puede observarse, estas actuaciones que pueden coincidir sin ninguna dificultad con las AGI contempladas en la LOUA no son actuaciones integradas en el sentido del artículo 2.1 del TRLSRU, aunque nada impide, a mi juicio, que los acuerdos suscritos entre la Administración autonómica y la municipal complementen las actuaciones a subvencionar por la AGE, con otras de carácter social, en cualquier caso, se echa de menos que desde la AGE se propicien esas actuaciones integradas.

Por último, y volviendo al TRLSRU, es preciso tener en cuenta que cualquier actuación en el medio urbano deben garantizar su viabilidad económica mediante la elaboración de una memoria de viabilidad, a la que nos referimos en páginas precedentes. Esta memoria debe acompañar a la modificación del planeamiento que haga posible la actuación o, si no fuera precisa modificación alguna del planeamiento, al acuerdo administrativo por el que se delimita la actuación.

Hay que destacar respecto del contenido del informe, la reiterada necesidad de concreción sobre que los costes de la actuación para los propietarios del ámbito no deben superar el deber de conservación, en este sentido véase el párrafo final de la letra a) del indicado artículo 22.5, también el párrafo final de la letra c) ${ }^{44}$. El informe quiere contener no solo los costes, sino también los incrementos de edificabilidad contenidos en la actuación y que puedan hacer aquélla más rentable, las posibles aportaciones de las Administraciones públicas, si las hubiere, y la posible inversión de terceros interesados en la actuación, o, finalmente, los compromisos de las empresas prestadoras de servicios energéticos, abastecimiento de agua o telecomunicaciones de financiar la parte de la actuación que afecte a sus servicios.

\subsection{Régimen jurídico de las actuaciones sobre el medio urbano}

Los derechos de los propietarios de construcciones, edificaciones y/o suelo en suelo urbanizado y que, en consecuencia, pueden verse afectados por actuaciones en el medio urbano se regulan en el artículo 14, en el que se establece el derecho a urbanizar o por ser más preciso completar la urbanización existente, edificar sobre unidad apta para ello, es decir, sobre una parcela tal y como aparece definida en el artículo

43 Artículo 144 LOUA.

44 Sobre la viabilidad económica de la L3R, Tejerina González, J. I., obra citada, p. 311, afirma que «la viabilidad económica se alcanza cuando los propietarios no tengan que aportar a la actuación una cantidad superior al $50 \%$ de lo que costaría construir su edificio actualizado». 
26.1.b) TRLSRU ${ }^{45}$ y, participar en la ejecución de las actuaciones de reforma o renovación o de dotación en un régimen de justa distribución de beneficios y cargas.

Esta participación en régimen de equidistribución de beneficios y cargas, reiterada en el artículo 9.6 TRLSRU, habrá de entenderse referida a las actuaciones de reforma o renovación, pero no a las de rehabilitación edificatoria, pues en ella resulta muy complicada la aplicación de esta técnica, significa que cada propietario asumirá los gastos de la actuación en proporción a su propiedad, y también, en relación con la misma recibirá superficie edificable. El principio de equidistribución es básico en nuestro Derecho Urbanístico, y el legislador ha querido afianzarlo en las actuaciones en el medio urbano ${ }^{46}$. Los efectos de la aprobación del instrumento de equidistribución (proyecto de reparcelación suele designarlo la legislación urbanística) se fijan en el artículo 23 TRLSRU, sin que presente peculiaridades a las que haya que hacer referencia en este momento.

Una alternativa a la equidistribución es la establecida en la letra c) del indicado artículo 14, reservada, a nuestro juicio, para aquellas actuaciones, fundamentalmente de dotación, en las que no sea posible la sustitución de la antigua propiedad por la nueva, su diferencia con la equidistribución «tradicional» parece consistir en que en la primera se produce la sustitución de la antigua propiedad por la nueva, mientras que en esta alternativa esa sustitución no existe, es decir se mantiene la antigua propiedad ${ }^{47}$, limitándose a la «distribución, entre todos los afectados, de los costes derivados de la ejecución y de los beneficios imputables a la misma, incluyendo entre ellos las ayudas públicas y todos los que permitan generar algún tipo de ingreso vinculado a la operación».

La letra d) del mismo artículo, formula un último derecho, que más parece una obligación, al establecer que la resolución administrativa que permita el inicio de la actuación, produce, de forma automática y por mandato legal, la afección real e inmediata al pago de las cuotas de urbanización de las fincas incluidas en el ámbito de ésta.

En cuanto a las cargas, se encuentran reguladas en el artículo 17, son la otra cara de la moneda de los derechos a que hemos hecho referencia, la más singular en el medio urbano es la de conservar, y a ella nos referiremos en el epígrafe siguiente, por lo que no nos detendremos en este momento.

El número 5 del mismo artículo establece quienes son los sujetos obligados a la realización de las actuaciones sobre el medio urbano, éstos serán, además de aquellos que disponga la legislación autonómica, los siguientes: a) los propietarios y titulares de derechos de uso en la proporción que establezca el contrato respecto de los bienes privados; b) las comunidades de propietarios y cooperativas de viviendas respecto a los elementos comunes de la construcción, edificio o complejo inmobiliario; c) la Administración Pública respecto a los elementos propios de la urbanización, siempre que no exista el deber del propietario de asumir su coste. De este modo distingue con nitidez la responsabilidad de cada sujeto respecto del objeto del que es «titular» ${ }^{48}$.

La iniciativa para proponer la ordenación de las actuaciones de transformación puede partir de la Administración, de las entidades dependientes de ellas o de los propietarios. En las actuaciones en el medio urbano, además, pueden partir de las comunidades de propietarios y agrupaciones de comunidades, cooperativas, propietarios de construcciones, edificaciones y fincas urbanas, en este punto la Ley es redundante, pues los propietarios se han mencionado al regular las actuaciones de transformación. También pueden adoptar la iniciativa, los titulares de derechos reales y cualquier sociedad que represente a alguno de los anteriores. Es claro que, la posibilidad de iniciar una actuación en suelo urbano está relacionada con las obligaciones derivadas de la clase de derechos de los sujetos que acabamos de referir. Así, p. e., la iniciativa de las comunidades de propietarios para promover la ordenación de la actuación solo es imaginable en aquellas actuaciones que incidan sobre elementos comunes de la edificación, e incluso, cuando la edificación precise de nuevos elementos comunes (p. e.: una rampa, un ascensor que produzca la ocupación de espacios públicos).

45 «Unidad de suelo, tanto en la rasante como en el vuelo o el subsuelo, que tenga atribuida edificabilidad y uso o sólo uso urbanístico independiente».

46 En este sentido, por citar solo una, la sentencia del Tribunal Supremo de 24 de junio de 2015, con cita de la sentencia del mismo Tribunal de 5 de marzo de 2007, dice, en lo que ahora nos importa: «[...] la regulación de las condiciones básicas que garanticen la igualdad de todos los españoles en el ejercicio de los derechos y en el cumplimiento de los deberes constitucionales; y que tiene que ver, también, con el respeto, en todo caso, del principio de equidistribución de beneficios y cargas; pues un incremento de los deberes de urbanización como es ese cuya posibilidad analizamos, comporta cuando menos un riesgo potencial de menoscabo de esa garantía de igualdad y de ese principio de equidistribución, [...]».

47 En este sentido, parece pronunciarse Tejerína González, obra citada, p. 309.

48 En igual sentido Tejedor Bielsa, J., 2013, p. 55. 
En cuanto a la participación (artículo 9.4), o si se prefiere, la posibilidad de pilotar la actuación, están facultados, naturalmente la Administración Pública que puede utilizar cualquier modalidad de gestión directa o indirecta, es decir, puede participar, p. e. a través de un concesionario o un agente urbanizador (o rehabilitador), etc.

En caso de no ejecutar las obras directamente y, dado que buena parte del art. 9.3 ha sido anulado por la sentencia del Tribunal Constitucional citada, la Administración en caso de acudir a un tercero ajeno a la misma, deberá seleccionarlo previa convocatoria de un concurso público que se regirá por la normativa de contratación pública, también podrá acudir a la incorporación de un medio propio o, finalmente, a encargar la misma a un consorcio previamente creado o una sociedad de capital mixto en el que la Administración debe ostentar una posición mayoritaria. De tratarse de actuaciones de transformación urbanística podrá acudirse a los medios que contemple la normativa urbanística para la ejecución del planeamiento.

EI TRLSRU reconoce el derecho a participar en estas actuaciones, además de a la Administración, a los propietarios de edificaciones, comunidades de propietarios, cooperativas y, en general, cualquier sociedad que intervenga en la actuación. Insistimos en lo dicho, que la participación de cualquiera de estas personas o entidades está relacionada, o hay que relacionarlo, con los sujetos obligados a que hace referencia el artículo 17.5 TRLSRU. Esta participación puede llegar hasta asumir la gestión de las obras, lo que podrán hacer, también, en asociación con otras personas físicas o jurídicas, el legislador parece estar pensando en la empresa urbanizadora (o rehabilitadora) del sistema de gestión por compensación.

Las obligaciones de los promotores de la actuación se regulan en el artículo $18^{49}$, pormenoriza en números sucesivos, los deberes de los promotores de actuaciones de transformación urbanística, actuaciones de dotación y actuaciones edificatorias. En las primeras, las obligaciones de los promotores son las típicas en estos procesos, a saber, entregar a la Administración suelo para dotaciones ya sean éstas para dotaciones locales o generales, entregar suelo con aprovechamiento urbanístico para incorporar al patrimonio público del suelo, costear y, en su caso, ejecutar todas las obras de urbanización, así como las infraestructuras de conexión previstas por el planeamiento, entregar a la Administración las obras e infraestructuras ejecutadas por formar parte de la urbanización, garantizar el realojo de los ocupantes legales, así como el derecho de retorno y, por último, indemnizar a los titulares de derechos sobre construcciones y edificaciones que deban ser demolidas y las obras, instalaciones, plantaciones y sembrados que no puedan conservarse.

En las actuaciones de dotación, los deberes a que se acaba de hacer referencia se atemperan en función del incremento de la edificación «media ponderada» que se produzca en el área delimitada como tal.

En las actuaciones edificatorias los deberes se limitan a los derechos de realojo y retorno de los ocupantes legales que tengan que ser desalojados como consecuencia de la actuación, así como los de indemnizar a los titulares de construcciones o edificaciones que deban ser demolidas y las obras e instalaciones que no puedan conservarse, hemos omitido la referencia a plantaciones y sembrados pues no es pensable que una actuación de edificación se encuentre con unas u otros.

A fin de facilitar la financiación de las actuaciones previstas por el planeamiento, la Ley reconoce a cualquiera de las personas y entidades que acabamos de enumerar para la realización de la actuación en el medio urbano, plena capacidad jurídica para realizar cualquier tipo de operaciones financieras, también las crediticias, que les permitan cumplir con su obligación de conservación y participar en las actuaciones de rehabilitación, regeneración y renovación [artículo 9.5.a)], lo que se recalca en la letra h) del mismo número ${ }^{50}$.

\subsection{La rehabilitación edificatoria}

Las actuaciones de edificación pueden ser de nueva edificación y sustitución de la edificación existente o de rehabilitación edificatoria, entendiendo por tales las que tienen por objeto dotar a las viviendas y edificaciones de las condiciones de funcionalidad, seguridad y habitabilidad previstos en la LOE.

En este epígrafe nos vamos a centrar en las actuaciones de rehabilitación edificatoria y mejora energética, que entendemos se configura en un elemento central de ese giro global, que supone centrar el urbanismo en las políticas de conservación, rehabilitación, regeneración y renovación urbana, en definitiva, en ese giro que hace de la sostenibilidad su hilo conductor.

49 No vamos a hacer una referencia pormenorizada a estas obligaciones pues son las típicas de cesión de suelos dotacionales, urbanización, cesión del suelo para realizar el aprovechamiento urbanístico que corresponde a la Administración, garantizar el realojo e indemnizar a los titulares de derechos existentes en el ámbito.

50 Véase también Tejedor Bielsa (2013), p. 56 y Allí Aranguren, J.-C., 2014, p. 221. 
La realización de estas actuaciones tiene como punto de partida, la obligación que la Ley impone a los propietarios de conservar su propiedad en las condiciones legales de seguridad, salubridad, accesibilidad universal y ornato [artículo 15.1.b)], así como, la realización de obras adicionales por «motivos turísticos o culturales, o para la mejora de la calidad o sostenibilidad del medio urbano» [artículo 15.1.c)], si bien estos últimos parecen exigir con carácter previo un requerimiento por parte de la Administración. Iglesias González, denomina al primero, deber de conservación ordinario y, al segundo, obras adicionales de conservación ${ }^{51}$, asociando solo al deber ordinario el límite del coste del cincuenta por ciento. A nuestro juicio, esta interpretación, aunque sugerente, es difícil de mantener de la lectura del Texto Refundido vigente, pues el número 2, no hace sino fijar el límite al deber de conservación a costa de los propietarios. Cuantificando, el número 3, ese límite en la mitad del valor actual del edificio de nueva planta ${ }^{52}$, de superarse dicho límite, los gastos suplementarios correrán a cargo de la Administración, siempre que las obras sirvan para obtener mejoras de interés general.

Esta regulación, por lo demás tradicional en nuestro derecho urbanístico, supone un beneficio para los propietarios más laxos en el cumplimiento de sus obligaciones, pues aquellos que mantienen periódicamente, probablemente, estén siempre dentro de los límites del artículo 15, mientras que los que no conservan, no mantienen, por la razón que fuere, se encontrarán un día que los costes de la rehabilitación pueden superar el límite del cincuenta por ciento. Nos parecería más adecuado a la idea de que la obligación de conservar no es solo un beneficio para el propietario, sino una obligación de interés general, limitar el deber de conservación en función de la capacidad económica de éste, de modo que, si carece de los recursos necesarios para el adecuado mantenimiento de su vivienda, debería poder acceder a medidas sociales y económicas de apoyo económico ${ }^{53}$. Y, para los restantes supuestos, la obligación de conservar no debe tener límites.

Esta obligación de conservar puede imponerse a los propietarios mediante órdenes de ejecución, que determinan la «afección real directa e inmediata» del inmueble al cumplimiento de la obligación de realizar las actuaciones previstas en la orden de ejecución. Y, en caso de inejecución, será la Administración quien deba actuar subsidiariamente ${ }^{54}$.

El número 4 del artículo que estamos estudiando dispone que, si el propietario incumple las órdenes de ejecución, y la Administración actúa subsidiariamente, el límite puede elevarse hasta el setenta y cinco por ciento del coste de reposición de la construcción, siempre que así lo disponga la legislación autonómica, parece que con esta previsión el legislador quiere abrir la posibilidad de que las CCAA «sancionen» al propietario que incumpla los requerimientos de la Administración.

Sobre el deber de conservación la jurisprudencia ha mantenido que «es una manifestación inequívoca de la función social que tiene el derecho de propiedad urbanística (artículo 33.2 de la CE) porque las razones de seguridad y de salubridad, e incluso de ornato público, son valores sociales indudables», así como que «La policía administrativa sobre las edificaciones no se limita a las licencias urbanísticas necesarias para alzarlas y ocuparlas sino que se prorroga en el tiempo, tras la conclusión de las obras al amparo de una licencia no caducada y conforme a la ordenación urbanística, mediante la exigencia de los deberes de conservación adecuada de los edificios» [STS 1-07-2002 (RC 7088/1998)]. En igual sentido la STS de 2606-2007 (RC 9002/2003).

A su vez, la sentencia del TSJ de Madrid de 6 de febrero de 2019 (RA 1118/2017), estudia qué se entiende por deber «normal» de conservación imputable al propietario, de modo que, lo que exceda aquél, no es exigible a éste, afirmando:

«obras de conservación de mejora o de reforma en fachadas o espacios visibles desde la vía pública por las expresadas razones de interés turístico o estético [artículo 15.1.c) del actual Texto Refundido de 2015], obras que también implican un deber que debe ser soportado por el propietario, pero presentan la diferencia de que todo lo que exceda del mantenimiento de las condiciones ordinarias de seguridad, salubridad y ornato públicos, es decir, del mantenimiento normal de los edificios no cabe en el deber de conservación a costa de su dueño, con la con-

51 Iglesias González, F., 2014, p. 60. Plantea si el deber de conservación ordinario no está sometido a límite alguno, aunque, a continuación mantiene que debe existir algún límite al deber de conservación en función de la situación técnica del inmueble.

52 Para el cálculo del límite del deber de conservación puede verse Tejerina González, J. I., 2014, pp. 303-305.

53 González Sanfiel, A., 2020, p. 37.

54 González-Varas Ibañez, S., 1998, p. 113, con referencia al TRLS de 1992, señala un doble deber, por un lado, de la Administración de requerir la conservación de la edificación y, por otro, del propietario de conservar en condiciones de estética, seguridad, salubridad y ornato las edificaciones de su propiedad. 
secuencia de que los gastos correspondientes deben correr con cargo a los fondos de la Administración que las ordene, respecto de todas las obras que rebasen este deber de conservación normal y persigan obtener mejoras de interés general por las razones turísticas y estéticas que se acaban de decir.».

Matizando a continuación que ese límite legal al deber de conservación se establece por la legislación autonómica en la mitad del valor de un edificio de nueva planta de similares características. La STSJ Andalucía. Sede de Sevilla de 20-04-2012 (RA 566/2011), se analizan los límites del deber de conservación, insistiendo en que dicho límite se encuentra en la mitad del valor actual de la edificación. También puede verse, la del mismo Tribunal, Sede Granada, de 27-09-2018 (RA 1032/2016), donde se coincide con la primera sentencia en cuanto al límite cuantitativo del deber normal de conservación.

Cuando las obras excedan del valor del deber de conservación, en lo que se rebase y siempre que supongan un beneficio para el interés general, como se dijo, se faculta para que dichos costes sean soportados por la Administración municipal, pues será ésta quien de forma normal imponga las órdenes de ejecución (número 5).

Podría plantearse si con esa referencia al «interés general», la Ley, está limitando la posible intervención de la Administración a actuaciones en inmuebles protegidos o, incluso, en aquellos que sin serlo tengan interés turístico, esta es la opinión de Barrero González ${ }^{55}$, si bien, limita la posible actuación de la Administración a los inmuebles catalogados que son los que de acuerdo con el artículo 157.3.B).a) LOUA no pueden ser demolidos, aun cuando sean declarados en estado de ruina ${ }^{56}$. A nuestro juicio, se trata de una visión anclada en un urbanismo de mercado, el interés general aboga por el principio de desarrollo urbano sostenible y, éste por la conservación y rehabilitación, así el art. 3.3.b), impone a los poderes públicos favorecer la rehabilitación y la ocupación de viviendas en desuso o, en el número 4, declara la vinculación del uso residencial al derecho a disfrutar de una vivienda digna.

El artículo 17.3 TRLSRU, concreta que, para las edificaciones, el deber de conservación supone satisfacer los requisitos básicos de la edificación establecidos en el artículo 3 de la Ley 38/1999, de 5 de noviembre, de Ordenación de la Edificación (LOE) ${ }^{57}$ y, actualizar sus instalaciones a las normas legales exigibles en cada momento.

55 Comentarios al artículo 155 LOUA, en Gutierrez Colomina (dir. y coor.) et al., 2004, p. 942.

56 De la misma opinión parece ser Jiménez-Blaco, A., 2007, pp. 394 y 395.

57 El artículo 3 establece los siguientes requisitos de funcionalidad, seguridad y habitabilidad:

a) Relativos a la funcionalidad:

a.1. Utilización, de tal forma que la disposición y las dimensiones de los espacios y la dotación de las instalaciones faciliten la adecuada realización de las funciones previstas en el edificio.

a.2. Accesibilidad, de tal forma que se permita a las personas con movilidad y comunicación reducidas el acceso y la circulación por el edificio en los términos previstos en su normativa específica.

a.3. Acceso a los servicios de telecomunicación, audiovisuales y de información de acuerdo con lo establecido en su normativa específica.

a.4. Facilitación para el acceso de los servicios postales, mediante la dotación de las instalaciones apropiadas para la entrega de los envíos postales, según lo dispuesto en su normativa específica.

b) Relativos a la seguridad:

b.1. Seguridad estructural, de tal forma que no se produzcan en el edificio, o partes del mismo, daños que tengan su origen o afecten a la cimentación, los soportes, las vigas, los forjados, los muros de carga u otros elementos estructurales, y que comprometan directamente la resistencia mecánica y la estabilidad del edificio.

b.2. Seguridad en caso de incendio, de tal forma que los ocupantes puedan desalojar el edificio en condiciones seguras, se pueda limitar la extensión del incendio dentro del propio edificio y de los colindantes y se permita la actuación de los equipos de extinción y rescate.

b.3. Seguridad de utilización, de tal forma que el uso normal del edificio no suponga riesgo de accidente para las personas.

c) Relativos a la habitabilidad:

c.1. Higiene, salud y protección del medio ambiente, de tal forma que se alcancen condiciones aceptables de salubridad y estanqueidad en el ambiente interior del edificio y que éste no deteriore el medio ambiente en su entorno inmediato, garantizando una adecuada gestión de toda clase de residuos.

c.2. Protección contra el ruido, de tal forma que el ruido percibido no ponga en peligro la salud de las personas y les permita realizar satisfactoriamente sus actividades.

c.3. Ahorro de energía y aislamiento térmico, de tal forma que se consiga un uso racional de la energía necesaria para la adecuada utilización del edificio.

c.4. Otros aspectos funcionales de los elementos constructivos o de las instalaciones que permitan un uso satisfactorio del edificio. 
La actualización de las instalaciones podría alcanzar a actuaciones de tanta importancia para la edificación y sus ocupantes, como las instalaciones contra incendios (CPI) o instalaciones de energía (calefacción y refrigeración). Según esta idea las instalaciones contra incendios tendrían que actualizarse periódicamente de acuerdo con la mejor técnica disponible (MTD) ${ }^{58} \mathrm{y}$, de igual forma se actuaría con las instalaciones de generación de energía que tanto influyen en la contaminación de la ciudad, esta idea es apuntada por Menéndez Rexach, quien la denomina cláusula de progreso para incorporar a las viejas edificaciones las mejoras técnicas disponibles ${ }^{59}$. Aun cuando coincido con Iglesias González, en que de la lectura de la exposición de motivos de la L3R se desprende que ésta no tiene carácter retroactivo ${ }^{60}$, dejando la determinación de la obligación o no de incorporar a la edificación las innovaciones técnicas a la legislación sectorial.

Por último, conviene hacer referencia, antes de terminar este epígrafe sobre las actuaciones de conservación de las edificaciones en suelo urbano, a las actividades de fomento realizadas por las Administraciones Públicas a través de los Planes de Vivienda, en efecto el PEV, establece como actuaciones subvencionables, las actuaciones de conservación relativas a la cimentación, estructura e instalaciones (artículo 43.1), las relativas a la mejora de la seguridad de utilización y de la accesibilidad. También, las relativas a la mejora de la eficiencia energética es objeto de ayudas en el indicado plan (artículo 36), a través de actuaciones en sistemas de calefacción, refrigeración, producción de agua caliente sanitaria, etc. El Plan de Vivienda, como sabemos, nada añade a la obligación de conservación, pues, el mismo, tiene por objeto fomentar la realización de determinadas actuaciones mediante un sistema de ayudas económicas, en consecuencia, es una norma que se mueve en la clásica actividad de fomento de la Administración.

No podemos acabar este epígrafe sin hacer referencia al "Informe de Evaluación de Edificios", regulado en el artículo 29 TRLSRU, como es sabido del indicado informe queda vigente exclusivamente el número 1, pues los números 2 a 6 ambos inclusive están afectados por la declaración de inconstitucionalidad y consiguiente nulidad que de ellos hizo la STC 143/2017, nulidad que tiene su causa en la incompetencia del Estado para regular esta materia. No obstante, lo que acabamos de decir, entendemos que el referido Informe es o puede ser una pieza esencial para contribuir a la conservación de las edificaciones, en función de la regulación que del mismo realicen las CCAA o los Ayuntamientos, pues la Ley se limita a posibilitar a la Administración competente a exigir el mismo a los propietarios de las edificaciones residenciales.

Como colofón de cuanto llevamos estudiado en relación con el deber de conservación. Poner de manifiesto, como, a nuestro juicio, el problema fundamental que plantea este deber es, que hasta la fecha, su regulación no ha sido suficiente para conseguir su objetivo, la pervivencia de las edificaciones existentes, pues tradicionalmente ha chocado con la pertinaz voluntad del propietario por declararlo en ruina, demolerlo, construir una edificación nueva y, de paso, extinguir los contratos de arrendamiento existentes ${ }^{61}$, quizás la menor protección de los arrendatarios en la vigente Ley de Arrendamientos Urbanos (LAU), aporte más argumentos en favor de la conservación de la edificación. Otro enemigo de la conservación es el planeamiento urbanístico, pues si éste otorga mayor aprovechamiento urbanístico (mayor edificabilidad) a las nuevas construcciones que, a las actuales, está introduciendo un incentivo perverso en favor de la renovación de estas, que en nada favorece su conservación.

\subsection{Los derechos de realojo y retorno}

Las actuaciones en el ámbito urbano suelen encontrar situaciones en las que las viviendas se encuentran ocupadas legalmente por personas distintas al propietario, ello supone que los ocupantes sean acreedores de los derechos de realojo y retorno, lo que supone la articulación de un derecho social ${ }^{62}$ que tiene su origen en la Ley de Arrendamientos Urbanos de 1964, y que la legislación urbanística amplió, dado que la vigente Ley de Arrendamientos Urbanos ${ }^{63}$ lo había dejado subsistente con carácter residual. En este sentido, la DA cuarta de la LS de 1992 ya recogía el derecho de realojo y retorno de forma similar a su regulación actual en el TRLSRU64.

58 Concepto, este de la MTD, muy depurado en el Derecho ambiental.

59 Menéndez Rexach, A., 2011, p. 20.

60 Iglesias González, F., 2014, p. 53.

61 En igual sentido Tejedor Bielsa, J., 2015, p. 11, quien apunta como mecanismos para corregir esta situación, el establecimiento de estímulos y la generación de «un tejido empresarial o cooperativo que garantice una gestión adecuada y sostenible en el tiempo».

62 La articulación de este derecho social puede evitar que una vez reformado el espacio urbano y rehabilitadas las viviendas, éstas entren, como dice González Sanfiel, 2020, p. 39, en un proceso de elitización.

63 DT 2. ${ }^{a}$ Ley 29/1994, de 24 de noviembre, de Arrendamientos Urbanos.

64 En igual sentido, puede verse Quintana López, T., 2014, p. 2.494. 
El derecho de realojo consiste en la garantía de un nuevo alojamiento para los ocupantes legales de inmuebles que constituya su residencia habitual, siempre que aquélla, obviamente, se encuentre dentro del ámbito de una actuación en el medio urbano. Se trata, a decir del número 3 del artículo 19 TRLSRU, de un derecho personal e intransferible, con la única excepción de los herederos forzosos o del cónyuge supérstite, y siempre que unos u otro acrediten la utilización de la vivienda como residencia habitual.

Los números 1 y 2 regulan el ejercicio del derecho de realojo en actuaciones sistemáticas, el primero, y de realojo y retorno en las asistemáticas, el segundo.

Así las letras a) y b) del número 1, disponen que la Administración expropiante [letra a)] o el promotor de la actuación [letra b)], deberán poner a disposición de los ocupantes legales viviendas en condiciones de venta o alquiler vigentes para las viviendas protegidas y de una superficie adecuada, dentro de las limitaciones de superficie de la vivienda protegida. La entrega de la vivienda de reemplazo deberá realizarse en igual régimen al que viniera disfrutando, y equivale al abono del justiprecio o, de compensación por la indemnización a que tiene derecho el titular de un derecho de arrendamiento.

El ocupante legítimo puede optar por recibir el justiprecio en metálico y renunciar a su derecho al realojo regulado en el TRLSRU. En consecuencia, en las actuaciones sistemáticas no se contempla el derecho de retorno.

La regulación de los derechos de realojo y retorno solo se reconocen para las actuaciones asistemáticas, siempre que no corresponda aplicar la expropiación, en cuyo caso sería de aplicación la regulación que hemos visto en el párrafo anterior. El número 2 del referido artículo 19, se establece la obligación del propietario de la edificación de facilitar un alojamiento provisional a las personas afectadas por la actuación que estuvieran ocupando legalmente un inmueble como vivienda y, además, facilitarles el retorno, todo ello por el tiempo que reste de contrato ${ }^{65}$.

Nuestros Tribunales vienen reconociendo este derecho a cualquier ocupante legal, así la sentencia del TSJ de Madrid de 8 de febrero de 2017 (RA 988/2016), afirma:

«[...] que establece una verdadera obligación de relaja de naturaleza urbanística porque para que surja el derecho de realojo se precisa que el ocupante tenga la condición de legal esto es que sea titular de un derecho real sobre la vivienda de la que ha de ser desalojado, esto es que sea propietario, usufructuario de la misma o al menos que goce de un derecho personal, esto es que se arrendatario. Incluso podría admitirse como ocupante legal al mero precarista esto es al poseedor con la aquiescencia del propietario.».

En igual sentido las sentencias del mismo Tribunal de 2-02-2006 (RA 393/2004); 16.03. 2016 (RA 527/2015; 20-04-2016 (RA 609/2015), entre otras muchas.

El realojo debe realizarse en una vivienda en el mismo ámbito de la actuación, o si no es posible, en el más próximo a la misma y, cuando esto no sea viable tendrán derecho al equivalente económico del derecho al realojo (número 5); dicha vivienda tendrá una superficie adecuada a las necesidades del titular del realojo y si es una persona con discapacidad, acorde con sus necesidades, entiendo que una superficie "adecuada» será, una superficie igual a la que venía disfrutando.

Una vez concluida la actuación, el propietario del inmueble deberá facilitar el retorno a una vivienda cuya superficie no sea inferior en un cincuenta por ciento a la anterior, siempre que tenga al menos noventa metros cuadrados, o no inferior a la que tuviera con anterioridad, si no alcanza dicha superficie, de características similares y ubicada en el mismo solar o en el entorno, de haberse derribado el edificio. Obviamente, como dice Quintana López, el retorno debe producirse a una vivienda que pueda material y jurídicamente ser ocupada ${ }^{66}$.

El precepto que estamos comentando, establece en el número 4 una serie de reglas procedimentales que pretenden garantizar la participación en el establecimiento de la actuación en suelo urbano de los ocu-

65 Opinión de Quintana López, T., citado, p. 2.495, este límite temporal excluye del derecho de realojo a las personas que ocupan una vivienda como precaristas, por el mero consentimiento del propietario, sin la existencia de contrato alguno.

No compartimos la misma pues, a nuestro juicio, discrepo que la mera fijación como límite de los derechos de realojo y retorno de la fecha del contrato, presuponga la voluntad del legislador de limitar los mismos a los contratos estipulados por escrito con fecha de vencimiento. Entendemos que, si el legislador hubiera pretendido limitar los derechos de realojo y retorno, exclusivamente, a quienes tuvieran formalizado un contrato, así lo hubiese hecho, sin embargo, para identificar a los titulares de estos derechos, utiliza una acepción tan amplia como "ocupantes legales», de donde no cabe sino interpretar que el legislador está incluyendo a todos aquellos en que se dé esa condición.

66 lbídem. 
pantes legales, de este modo impone: a) a la Administración la obligación de identificarlos y notificarlos, concediéndoles un trámite de audiencia que coincidirá con el de información pública, cuando sea preceptivo y ya sabemos que lo es; b) durante dicho trámite los ocupantes podrán acreditar sus títulos y solicitar el reconocimiento del derecho o renunciar a él; c) terminado el trámite de audiencia e información pública, cuando sea necesario, la Administración publicará una relación de las personas con derecho a realojo, notificándoselo a los interesados; d) la Ley autoriza que después de estos trámites se reconozca el derecho a otras personas que acrediten los requisitos legales. Contra los listados aprobados por la Administración, como mantiene Quintana López, pueden oponerse los propietarios, si entienden que la relación aprobada por la Administración contiene personas que no reúnen los requisitos legalmente establecidos ${ }^{67}$ o los ocupantes, si alguno de ellos no ve reconocido su derecho o no lo ve reconocido en los términos legales.

\section{CONCLUSIONES}

A modo de recapitulación final, conviene recordar por donde empezamos, el derecho a una ciudad es un derecho de los ciudadanos, un derecho si se quiere emergente, que aboga porque los ciudadanos sean protagonistas de su ciudad, modelándola de acuerdo con sus intereses, con los intereses generales. La legislación urbanística tradicionalmente ha propiciado la participación de los ciudadanos en el proceso de aprobación de los instrumentos de planeamiento y gestión, pero se ha tratado de una participación más formal que real, el nuevo protagonismo de los ciudadanos debe ser, como dice la Constitución, real y efectiva y en esa dirección deben ir los instrumentos que la articulen.

Ese derecho a la ciudad armoniza con el principio de desarrollo urbano sostenible, del que se hace un amplio eco la legislación sobre el suelo. En efecto, el TRLSRU tras afirmar de forma clara este principio, reitera, como ya hiciera la Constitución, la necesidad de orientar las políticas públicas hacia el uso racional de los recursos naturales, entre los que, obviamente, se encuentra el suelo, armonizando los requerimientos de la economía, el empleo, la cohesión social, la igualdad de trato y de oportunidades, la salud y la seguridad de las personas y la protección del medio ambiente. Lo que, descendiendo a aspectos más concretos, implica la necesidad de abandonar ese urbanismo expansionista, característico del siglo XIX y, buena parte del XX, y volver la vista hacia la ciudad, no se trata ya de crear nueva ciudad, sino de mejorar la existente.

En este proceso que parece irreversible, aunque todavía no se ha enfrentado a un periodo largo de expansión económica, que presione en dirección contraria, resulta imprescindible contar con instrumentos jurídicos adecuados.

EI TRLSRU hace de las actuaciones en el medio urbano el instrumento básico de esa nueva práctica urbanística, tanto para conservar las edificaciones existentes como para rehabilitarlas mejorando su accesibilidad, imprescindible en una sociedad cada vez más envejecida, para mejorar su eficiencia energética necesaria para atenuar y ralentizar el cambio climático, como es sabido, la ciudad es el mayor consumidor de recursos naturales y el mayor productor de emisiones de gases efecto invernadero.

Sin embargo, alguno de los instrumentos concretos que deben favorecer la rehabilitación y conservación de la ciudad, están diseñados por el legislador pensando en la edificación, en la vivienda, como un bien fácilmente sustituible, si no se conserva, se demuele (el deber de conservación termina donde empieza la declaración de ruina económica, o simplemente ruina), así limita el deber de conservación en unos márgenes estrechos, a nuestro juicio, este deber solo debería limitarse para aquellas personas que carezcan de recursos económicos para su realización y, en esos casos, los poderes públicos debieran llegar hasta donde los ciudadanos no pueden.

Junto a estas intervenciones, la ciudad precisa de aquellas otras que tienen por objeto promover actuaciones de renovación y regeneración del tejido urbano, necesarias, fundamentalmente, en aquellas zonas más degradadas de la ciudad, cuyo deterioro físico suele coincidir con un empobrecimiento en lo económico y un menoscabo social, por ello se ha criticado que la Ley solo posibilite las intervenciones integrales, a nuestro juicio, debería potenciarse de forma resuelta las intervenciones que integren lo urbanístico, con lo económico y con lo social. Intervenciones que deberían tener por objeto, además de la renovación urbana, promover la estabilidad de la población residente en su barrio y, favorecer la diversificación social, para hacer barriadas más inclusivas y abiertas.

67 Ibídem, p. 2.502. 
Junto a estas actuaciones en barriadas periféricas o no, es preciso actuar en el centro de nuestras ciudades, dotándolas de nuevas instalaciones y servicios, y propiciando la conservación de su carácter residencial para evitar su abandono y, consecuente gentrificación de los centros urbanos. Así como, aquellas otras que pongan en valor la conservación del patrimonio edificado, pues tenemos la obligación de legar a nuestros hijos la ciudad que recibimos de nuestros padres. En la línea apuntada resulta de gran interés la lectura de la sentencia del TS de 26 de enero de este año (RC 8090/2019).

Si algo en común tienen las distintas actuaciones señaladas, es su falta de atractivo económico, en general la iniciativa privada es refractaria a ellas, los costes son altos y los beneficios esperados escasos, por ello, la mayoría de las actuaciones en la ciudad están necesitadas del impulso y la aportación de importantes recursos públicos. En este punto, el régimen jurídico previsto en el TRLSRU, que en buena medida reproduce los esquemas de las actuaciones de ejecución del planeamiento características del suelo urbanizable, han tenido escaso seguimiento. No creemos que en el futuro exista una gran competencia para asumir la gestión en la mayoría de las actuaciones enumeradas. Ni parece que la equidistribución sea el mecanismo más adecuado para la ejecución de actuaciones en el medio urbano, por ello, parece un acierto que el legislador haya previsto un régimen alternativo. En cualquier caso, deberían revisarse las experiencias de gestión de las actuaciones realizadas al amparo de los planes URBAN o de los actuales EDUSI y, sacar conclusiones con relación a su posible generalización.

\section{REFERENCIAS BIBLIOGRÁFICAS}

Alenza García, J. F. (2018). Los municipios ante los retos de la prevención, el aprovechamiento y la eliminación segura de los residuos. En Alonso Ibañez, M. R. (dir.), Retos del desarrollo urbano sostenible e integrado (pp. 269-296) Tirant lo blanch.

Alonso Ibañez, M. R. (2012). De la política urbanística a la política urbana. Revista de Derecho Urbanístico y Medio Ambiente, 46(277), 13-28.

Alonso Ibañez, M. R. (2014). Las repercusiones urbanísticas y territoriales de un modelo agotado de crecimiento económico. Revista Vasca de Administración Pública, 99-100 (número especial), 255-270. https://apps.euskadi. eus/t59auUdaWar/R2/verArticulo?numejem=100\&tipo=R\&seccion=38\&correlativo=1\&contenido=10\&locale=es

Alonso Ibañez, M. R. (2016). Las actuaciones de regeneración y renovación urbanas. Práctica urbanística: Revista mensual de urbanismo, 138, 42-55.

Alonso Ibañez, M. R. (2017). La viabilidad económica de los procesos de regeneración urbana. En F. García Rubio, R. Camp i Batalla y L. Vandelli (coords.), Las nuevas perspectivas de la ordenación urbanística y del paisaje, smart cities y rehabilitación: una perspectiva hispano-italiana. Fundación, Democracia y Gobierno Local.

Alonso Ibañez, M. R. (2020). Un territorio para un derecho urbanístico sostenible. En A. González Sanfiel (dir.), Nuevo Derecho Urbanístico: simplificación, sostenibilidad, rehabilitación (pp. 131-164). Aranzadi Thomson Reuters y Universidad de La Laguna.

Alli Aranguren, J.-C. (2014). La Ley 8/2013, de 26 de junio, de rehabilitación, regeneración y renovación urbanas. Revista Vasca de Administración Pública, 99-100 (número especial), 209-239. https://apps.euskadi.eus/ t59auUdaWar/R2/verArticulo?numejem=99\&tipo=R\&seccion=38\&correlativo=1\&contenido=8\&locale=es

Bandrés Sánchez-Cruzat, J. M. (2014). El derecho a la ciudad. Cuadernos de Derecho Local, 35, 97-103. http://hdl. handle.net/10873/1579

Barrero González, E. (2004). Comentarios al artículo 155 LOUA. En V. Gutierrez Colominas y A. Cabral GonzálezSicilia (dirs.), Comentarios a la Ley de Ordenación Urbanística de Andalucía. Thomsom-Aranzadi.

Bustillo Bolado, R. O. (2014). El desarrollo sostenible como concepto jurídico y como principio constitucional. En R. O. Bustillo Bolado y M. F. Goméz Manresa (dirs.), Desarrollo sostenible: análisis jurisprudencial y políticas públicas. Thomsom-Aranzadi.

Castellvi Martínez, E. (2004). En V. Gutierrez Colominas (dir. y coord.) et al., Comentarios a la Ley de Ordenación Urbanística de Andalucía (p. 890). Thomsom-Aranzadi.

Cuyas Palazón, M. (2018). Los retos de la planificación estratégica. En M. R. Alonso Ibañez (dir.), Retos del Desarrollo Urbano Sostenible e Integrado (pp. 133-159). Tirant lo Blanch.

Fariña, J. (3 de enero de 2012). Smart Cities, los inventos del TBO. El blog de José Fariña. https://elblogdefarina. blogspot.com/2012/01/smart-cities-los-inventos-del-tbo.html

Fernández de Gatta Sánchez, D. (2016). Rehabilitación, regeneración y renovación urbanas. Planificación y gestión. Revista Jurídica de Castilla y León, 39 (monográfico), 1-50. https://www.jcyl.es/web/jcyl/AdministracionPublica/es/ Plantilla100Detalle/1215245063566/Publicacion/1284557094582/Redaccion

Gardini, G. (2020). Hacia la «ciudad justa». Planificación y regeneración urbana: la experiencia italiana. En A. González Sanfiel (dir.), Nuevo Derecho Urbanístico: simplificación, sostenibilidad, rehabilitación (pp. 165-221). Thomson Reuters Aranzadi y Universidad de La Laguna. 
Gifreu i Font, J. (2017). Las actuaciones sobre el medio urbano como nueva frontera de las políticas públicas al servicio de la sostenibilidad territorial y urbanística. En F. García Rubio, R. Camp i Batalla y L. Vandelli (coords.), Las nuevas perspectivas de la ordenación urbanística y del paisaje, smart cities y rehabilitación: una perspectiva hispano-italiana. Fundación, Democracia y Gobierno Local.

González del Barrio, A. (2018). Las ciudades invisibles. Práctica urbanística: Revista mensual de urbanismo, 154.

González Sanfiel, A. (2020). Nuevo derecho urbanístico: simplificación, sostenibilidad, rehabilitación. en A. González Sanfiel (dir.), Nuevo Derecho Urbanístico: simplificación, sostenibilidad, rehabilitación (pp. 29-46). Thomson Reuters Aranzadi y Universidad de La Laguna.

González-Varas Ibáñez, S. (1998). La rehabilitación urbanística. Aranzadi.

Gutiérrez Colomina, V. (dir. y coord.), González-Sicilia Cabral, A. (dir. y coord.), Romero Hernández, F. (coord.), Rivero Ysern, J. L. (coord.), Antúnez Torres, D., Barrero González, E., Carrillo Benito, E., Cano Murcia, A. y Castellví Martínez, E., Ferrer Morató, J., Gutiérrez Julián, F., Martínez Rivas, F. J., Morente del Monte, J. M., Olmedo Pérez, S., Pérez Ándres, A. A., Porto Rey, E. y Romero Gómez, F. (2004). Comentarios a la Ley de Ordenación Urbanística de Andalucía. Ley 7/2002, de 17 de diciembre (Comentarios de E. Barrero González al artículo 155 LOUA). Thomson-Aranzadi.

Harvey, D. (2008). Espacios de esperanza (traducido por C. Piña Aldao). Akal.

Iglesias González, F. (2014). La regulación estatal del deber de conservación de inmuebles. Ciudad Y Territorio Estudios Territoriales (CyTET), 46(179), 51-62. https://recyt.fecyt.es/index.php/CyTET/article/view/76288

Iglesias González, F. (2015). Siete medidas urgentes para salvar el urbanismo. Revista de Derecho Urbanístico y Medio Ambiente, 49(301), 77-150.

Jiménez-Blanco Carrillo de Albornoz, A. (2007). La ejecución del planeamiento. En M. Rebollo Puig (coord.), Derecho urbanístico y ordenación del territorio en Andalucía. IUSTEL.

López Ramón, F. (2007). Principios generales y urbanismo sostenible en la Ley de Suelo 8/2007, de 28 de mayo (RCL 2007, 768). Revista de Urbanismo y Edificación, 16, 15-22.

Menéndez Rexach, A. (2009). Urbanismo sostenible y clasificación del suelo. Revista Catalana de Derecho Público, 38, 119-146. http://revistes.eapc.gencat.cat/index.php/rcdp/article/view/2177

Menéndez Rexach, A. (2011). Instrumentos jurídicos para la regeneración urbana. Revista de Derecho Urbanístico y Medio Ambiente, 45(270), 13-50.

Menéndez Rexach, A. y Mata Olmo, R. (2014). Por la rehabilitación, la regeneración y la renovación urbanas. Revista Ciudad y Territorio Estudios Territoriales (CyTET), 46(179), 5-9. https://recyt.fecyt.es/index.php/CyTET/article/ view/76283

Menéndez Rexach, A. (2020). El desarrollo territorial y urbano sostenible como principio político y jurídico global. En A. González Sanfiel (dir.), Nuevo Derecho Urbanístico: simplificación, sostenibilidad, rehabilitación (pp. 49-91). Thomson Reuters Aranzadi y Universidad de La Laguna.

Moreno Molina, A. M. (2008). Urbanismo y Medio Ambiente. Las claves jurídicas del planeamiento urbanístico sostenible. Tirant lo Blach (Monografías).

Navarro Cano, N. (2016). Gobernanza y desarrollo inclusivo en materia de accesibilidad y rehabilitación de ciudades emergentes. Revista WPS Review International on Sustainable Housing and Urban Renewal, 4, 68-82 (número monográfico sobre Gobernanza Urbana).

Parejo Alfonso, L. (2015). Urbanismo temporal, derecho a la ciudad y marco estatal de las políticas urbanas. Revista Práctica Urbanística, 136, 6-16.

Ponce Sole, J. (2013). Políticas Públicas para afrontar la regeneración urbana de barrios degradados. Una visión integrada desde el Derecho. Revista Aragonesa de Administración Pública, 41-42, 11-70. http://www.unizar.es/ carmeng/documents/PoliticasRegeneracion.pdf

Ponce Sole, J. (2019). El derecho a la ciudad y la Nueva Agenda Urbana: una aproximación integrada y sistemática a los derechos en la ciudad, con referencia al derecho a la vivienda. En J. Ponce Solé, Wellington Migliari y O. Capdeferro Villagrasa (coords.), El derecho, la ciudad y la vivienda en la nueva concepción del desarrollo urbano: desafíos transnacionales y transdisciplinarios de la gobernanza en la Nueva Agenda Urbana (pp. 115-151). Atelier.

Quintana López, T. (2014). Los derechos de realojo y retorno. Antecedentes y regulación estatal en el modelo de urbanismo sostenible. Revista Vasca de Administración Pública, 99-100, 2.479-2.503 (número especial). https://apps.euskadi. eus/t59auUdaWar/R2/verArticulo?numejem=100\&tipo=R\&seccion=38\&correlativo=1\&contenido=106\&locale=es

Sánchez Goyanes, E. (2007a). Comentarios al artículo 2 Ley del Suelo de 2007. En Sánchez Goyanes (dir.), Ley del Suelo. Comentario sistemático de la Ley 8/2007, de 28 de mayo, del Suelo. El Consultor y La Ley.

Sánchez Goyanes, E. (2007b). El deber de conservación, las órdenes de ejecución y la declaración de ruina. En Sánchez Goyanes (dir.), Ley del Suelo. Comentario sistemático de la Ley 8/2007, de 28 de mayo, de Suelo. El Consultor y La Ley.

Sibina Tomás, D. (2007). Deber de conservación y rehabilitación de los inmuebles y derecho de realojamiento y retorno. Su interrelación con el acoso inmobiliario. Cuadernos de derecho local, 14, 121-146.

Tejedor Bielsa, J. (2013). Nuevos instrumentos de planificación y gestión de la rehabilitación y regeneración urbana. Revista Aragonesa de Administración Pública, (15, número extraordinario monográfico dedicado a: Rehabilitación y regeneración urbana en España), 27-72. 
Tejedor Bielsa, J. (2015). Nuevo paradigma normativo sobre la ciudad: Retornando a la ciudad tradicional. Revista Informes de la Construcción, 67(Extra-1) (artículo m022). http://dx.doi.org/10.3989/ic.14.046

Tejerina González, J. I. (2014). Incidencia de la normativa urbanística vasca de la Ley 8/2013 de Rehabilitación, Regeneración y Renovación Urbanas. Revista Vasca de Administración Pública, 98, 291-327. https://apps.euskadi. eus/t59auUdaWar/R2/verArticulo?numejem=98\&tipo=R\&seccion=41\&correlativo=1\&contenido=2\&locale=es

Vaquer Caballería, M. (2007). Estudio preliminar. En L. Parejo Alfonso y G. Roger Fernández, Comentarios a la Ley de Suelo (Ley 8/2007, de 28 de mayo) (pp. 19-58). IUSTEL.

Zamorano Wisnes, J. (2015). El suelo urbano y las operaciones de transformación urbanística en la legislación del suelo: evolución y régimen jurídico. Revista de Derecho Urbanístico y Medio Ambiente, 298, 47-86. 